\title{
Research on Intelligent Manufacturing Development Approach for China's Local Valve Industry
}

\author{
Victor Chang \\ Department of Computing, Engineering and Digital Technologies, \\ Teesside University, Middlesbrough, UK, and \\ Yuanyuan Kate $\mathrm{Xu}$, Jingqi Zhang and Qianwen $\mathrm{Xu}$ \\ Xi' an Jiaotong-Liverpool University, Suzhou, China
}

\begin{abstract}
Purpose

The purpose of this paper is to investigate the current situation of China's local valve industry, the maturity of intelligent manufacturing and the way to promote intellectual development.
\end{abstract}

\section{Design/methodology/approach}

Firstly, a macro analysis of the valve market environment from the domestic and international perspective was conducted. Secondly, online surveys and in-depth interviews were administered to understand the current status of IM development and future development goals. Finally, case studies were conducted to demonstrate whether the hypothesis of the development approach is feasible.

\section{Findings}

This study finds that the overall maturity level of the local valve industry is still in the planning stage since the local valve industry lacks concentration and relatively scattered. In addition, the 
feasible development approach is dependent on smart devices to improve production efficie ncy, ensure quality management and effectively control costs.

\section{Research limitations}

The research is conducted and focused on the Yangtze River Delta region, instead of the whole country and the size of the sample is small. Therefore, there may be some characteristics omitted in the analysis.

\section{Implications}

Manufacturers can upgrade to smart manufacturing through intelligent software platforms in order to complete an automatic interaction of data and devices. In addition, manufacturers should complete cross-regional collaborative development through the Industrial Internet of Things.

\section{Originality/value}

There is little or none of research work completed for the development strategy of the valve industry internationally. Therefore, research findings of this area can provide a fundamental understanding of China's local valve industry and contribute to the existing knowledge.

Keywords: Intelligence manufacturing; China local valve industry; Development approach; Smart devices; Smart factory 


\section{Introduction}

The aim of the paper is to develop a research development approach for intelligent manufacturing in the local Chinese valve manufacturing industry. The manufacturing industry has a profound impact on economic and societal progress. As Premier Li Keqiang said, China is a big manufacturing country, but it is not a manufacturing power (Keqiang, 2017). Today, many manufacturing sectors are still at the low-end level. This is the case with China's local valve manufacturing industry. Intelligent manufacturing has brought new opportunities to the strategic transformation of China's local valve manufacturing enterprises and is also the main direction of their strategic transformation and upgrading. In the face of the current situation and external environment of China's local valve industry, what kind of development approach should they seek? What difficulties and challenges might be faced and recommendations for the future?

\subsection{Background}

Technology advances have always driven improvements in industrial productivity and the start of industrial revolutions. Since the first industrial revolution in 1784, three industrial revolutions have greatly promoted major changes in various fields of human society, and world-famous powers of manufacturing industries like Germany and the United States have emerged.

Today, from the perspective of economic recovery and growth drivers, manufacturing is an important engine for global economic recovery. The fourth industrial revolution initiated in the 21 st century, it is based on a cyber-physical system that links real objects with virtual objects through an information network. It combines digital, physical and biological systems. Intelligent manufacturing provides effective information to support accurate decision making in real-time through a variety of high information technologies and its convergence with existing manufacturing technologies. The ultimate goal of intelligent manufacturing is aiming to improve competitiveness through the convergence of information technologies in order to secure a new growth engine.

Whether it is the 'Industrial Internet' in the United States or the 'Industry 4.0' in Germany, it is based on intelligent manufacturing, to enhance its position and dominance in the new round of global industrial division of labor and value chain. The Chinese manufacturing industry is facing a large but not strong market, and the current situation of overcapacity happens in the low-end manufacturing sector. A new generation of innovative technologies to enhance productivity and promote economic growth will create a new pattern of global manufacturing competition, so intelligent manufacturing is a new opportunity and an inevitable choice for Chinese manufacturing. In 2015, China State 
Council unveiled its first 10-year national plan to reform the Chinese manufacturing industry, entitled 'Made in China 2025' (Chinese State Council, 2015). This national strategic plan will transform China from a large manufacturing power to a strong manufacturing power in the next 30 years. Therefore, 'Intelligent manufacturing' will become the main direction of Chinese manufacturing transformation $(\mathrm{Ji}, 2015)$.

\subsection{Research Purpose}

Although the Chinese government has put intelligent manufacturing as the national strategy, many low-end manufacturing fields have not yet to form a clear development plan and approach. The valve industry structure is relatively fragmented, with manufacturers from large multinational companies to small private companies are all competing in this industry. The global top ten manufacture rs account for less than $30 \%$ of the total market revenue. From a regional perspective, North America is the largest production area and a leader in the entire valve industry. Europe and China also produce a large number of valves every year.

From the current situation of China's local valve manufacturing industry, domestic and international market competition and demand, it can be seen that China valve companies are weaker in terms of technological innovation than international manufacturers, and there is no mature and effective intelligent manufacturing model. China's top ten valve enterprises such as Neway, CNNC Sufa Technology Industry, Jiangsu Shentong Valve, Beijing Valve Plant and other enterprises are also in the process of exploring the development approach of intelligent manufacturing. Therefore, an indepth research is needed on the development approach of intelligent manufacturing in the valve manufacturing industry.

\subsection{Deductive Approach of Literature Review}

Following the background and purpose above, it is clear that this new industrial revolution provides China valve manufacturers with a rare and significant opportunity. They must carry out industrial technology reform and optimization and upgrade in the direction of intelligent manufacturing, incrementally drive stocks, improve its competitiveness, and move into a high-end position of the value chain in the international market.

In the beginning, authors analyzed and answered the following three literature questions through access to relevant literature and theories. The first question is "What is the history of Intelligent Manufacturing and current trends in China?" Authors will view the global manufacturing landscape, the current status and future trends of intelligent manufacturing development. The second question is “What's the current situation of China's local valve industry and its development direction?" Through 
a study of the present situation, difficulties and future opportunities of China valve manufacture rs, the review will clarify the major direction for China's local valve industry development in the future. The third question is "What is the current situation of intelligent manufacturing development in China local valve industry?" Finally, the conclusions and suggestions are given after data collection and analysis.

\subsection{Overview of Research Design}

The research design of this dissertation is to answer two research questions raised by reviewing the existing literature and demonstrating whether the relevant hypotheses are supported in this process. The authors adopted the mixed methods design by integrating survey, interview and case study.

Firstly, online surveys were administered to the manufacturers in the Yangtze River Delta region. It includes those that have not yet planned, be in the process of preparation, or are already executing IM management. The purpose of the survey is to understand the scale and current status of IM development in the most developed regions of China.

Secondly, employees of well-known local valve companies were interviewed to understand their manufacturing and information technology situation, difficulties and future development goals. In addition, the author combines two case studies of representative companies to demonstrate whether the hypothesis of the development approach is feasible.

Two research questions and three hypotheses are proposed in this research design.

Q1: What is the level of maturity of intelligent manufacturing capability in China's local valve industry?

Q2: What is the feasible development approach for China's valve manufacturers to develop intellige nt manufacturing? This question contains three hypotheses regarding the three stages of the development path.

H1: The use of digital smart devices is the foundation of intelligent manufacturing development $\mathrm{H} 2$ : Intelligent workshops and smart factories are the only ways to successfully develop smart manufacturing

H3: It is a new innovation and future of intelligent manufacturing development to realize crossregional integration among companies and collaborative development through Internet technology. 
Finally, authors can provide recommendations on the cross-industry and cross-regional collaboration and resource sharing through the Internet of Things and the Internet, improving service quality are the future and vision of smart manufacturing.

\subsection{Overview of Research findings and implications}

This study finds that the overall average level of intelligent maturity of China's local valve industry is still at the planning level; the local valve industry is lack of concentration and relatively scattered.

Regard to IM development approach of the local valve industry; information technology is firstly used to connect smart devices to realize an automation production process. Then, to achieve intelligent factories, sensing technologies are employed to collect data from the production process. Finally, the interconnection between devices and data is realized through Industrial Ethernet. The data is analyzed to provide support for business strategy.

Since the research on the development strategy of China's local valve industry, whatever in China and abroad is almost blank, therefore, this research has actively promoted the development of this field. It has a positive instruction function for companies that are currently seeking a feasible development strategy. Manufacturers can upgrade to smart manufacturing through intelligent software platforms in order to complete an automatic interaction of data and devices. In addition, manufacturers should complete cross-regional collaborative development through the Industrial Internet of Things.

\section{Literature Review}

This section is aimed to answer three literature review questions (LQs). Extensive literature was reviewed during the research process, including academic journals, working papers, textbooks, and government reports. Many other resources have adopted such approahces, including web-based journals and news reports, which can provide some supplementary points of view and up-to-date research data to support follow-up investigations.

\subsection{LQ1: What is the History of IM and Current Trends in China?}

Intelligent Manufacturing (IM) is a broad manufacturing concept that is designed to optimize the physical processes of production and product transactions by leveraging advanced information and manufacturing techniques. The word 'Intelligence' covers the creation of flexible manufacturing processes throughout the product lifecycle, improving product quality and service levels, and 
responding to changes in business and market demand with low cost to increase the competitiveness of manufacturing companies. According to Stock and Seliger (2016), intelligent manufacturing plays a very important role in a sustainable environment. Intelligent manufacturing can contribute to sustainability in terms of raw materials, parts and manufacturing processes. Especially in the industry 4.0 , with intelligent systems, the allocation of resources in the manufacturing process can be more efficient.

\subsubsection{The History of Intelligent Manufacturing}

The study of intelligent manufacturing can be traced back to the 1970s and 1980s. Professor Wright of New York University and Professor Bourne of Carnegie Mellon University published the book 'Manufacturing Intelligence', and the first proposed the concept of intelligent manufacturing (Wright and Bourne, 1988). They also pointed out that the purpose of intelligent manufacturing is to improve the modularity of skills and expertise of manufacturing technicians by integrating technical knowledge, manufacturing processes, and machine auto-control so that smart devices can be produced in small batches without human intervention. In the 1990s, the concept of intelligent manufacturing was further expanded. Japan, the United States and Europe jointly launched international collaborative research on intelligent manufacturing. They proposed that IMS is an intelligent activity throughout the entire manufacturing process, and combined with smart machines to integrate the various parts in the process in a flexible way. It will be an advanced system that delivers maximum productivity to the human being (Huiwen, 2016).

Chen (2017) from The University of Michigan conducted research on the development of manufacturing technology and indicated that it has always revolved around three basic elements: production efficiency, quality management and cost management. To improve the productivity and efficiency of manufacturing industry has always been the key issue in the industrial revolution.

The development history of the human industrial revolution is a history of the innovation of manufacturing technology (Figure 1). Lukač (2015) mentioned in his speech that the first industrial revolution at the end of the 18th century transformed handcrafting into mechanical equipment through water and steam-powered production mode, it has greatly increased the productivity of human manufacturing. In the second industrial revolution in the early 20th century, the development of manufacturing technology became a large-scale high-speed production based on electrical energy, which made the manufacturing efficiency of the manufacturing industry reach a new level. The characteristics of the third industrial revolution are based on the combination of advancements in electronics and information technology, leading the manufacturing industry to automated production mode. 


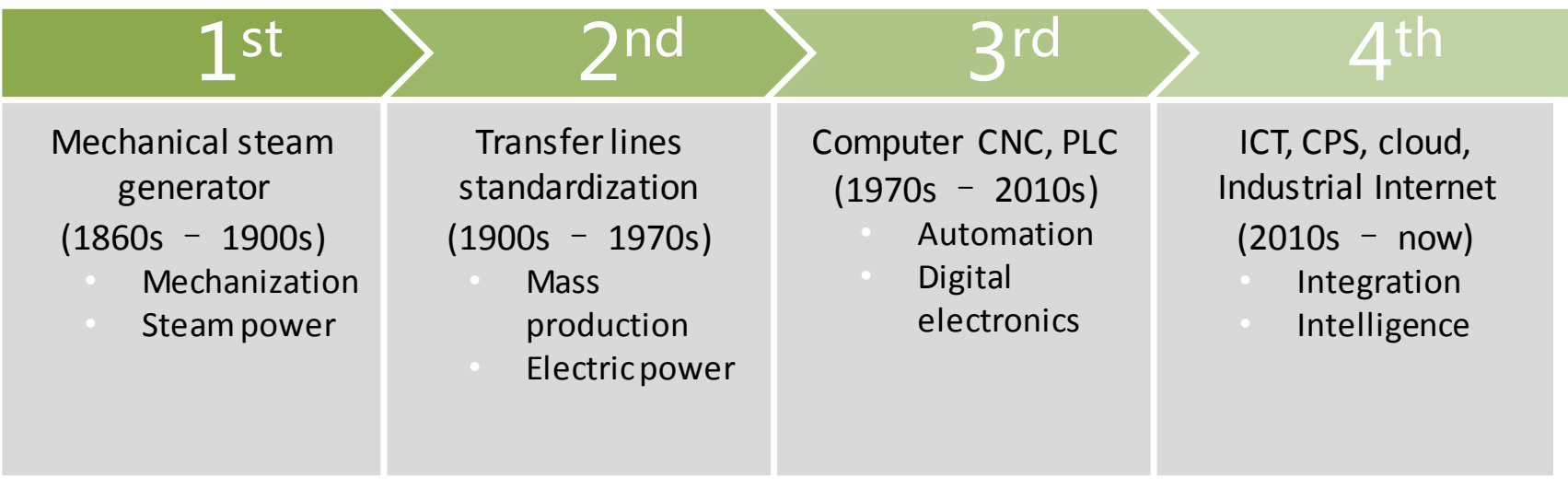

Figure 1. The progress and characteristics of industrial revolutions (Chen, 2017)

Nowadays, with the development of information technology and artificial intelligence, all countries have actively explored in the wave of manufacturing transformation and made great progress in the research and practice of intelligent manufacturing. We call it the fourth industrial revolution, and we found that internet technology and smart devices are gradually changing the way our manufacturing process and increasing the productivity of the entire industry. In terms of a white paper of Skill Development for Industry 4.0 (Figure 2), it stated that the US government launched the Advanced Manufacturing Partnership in 2011 (Obama, 2011) and launched the National Network for Manufacturing Innovation in 2014. Germany announced the Industry 4.0 strategy in 2013 (Kagermann et al., 2013). The United Kingdom proposed the British Industry 2050 Strategy in 2013, France announced the French New Industrial Plan in 2016. In 2015, the Chinese government officially announced 'Made in China 2025' as the 10-year plan and roadmap for the manufacturing industry (Lee, 2015). Japan developed its Social 5.0 Strategy of revitalization and robot strategy (Taki, 2017), and South Korea launched the Manufacturing Innovation 3.0 Program. 


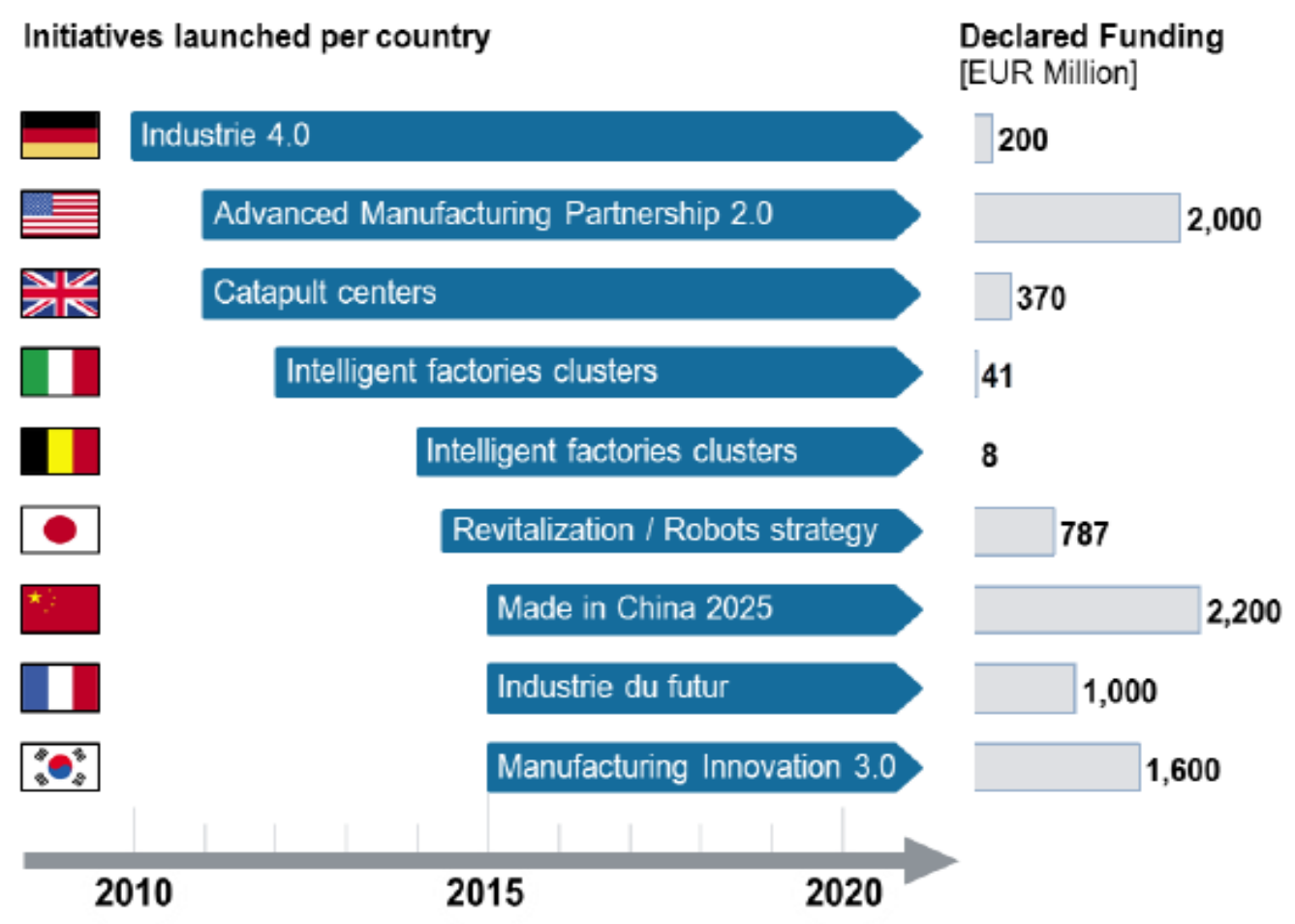

Figure 2. Worldwide Initiatives and Related Investment Announced

From the perspective of national strategic focus, both the developed and emerging economies have attached great importance to the development of the manufacturing industry. All countries are aware that manufacturing is an important engine that drives the global economic recovery. They have given a series of policy support to develop core technologies in advanced manufacturing systems field in order to seize a higher position of international manufacturing technology competition and continuously expand its competitive advantage.

\subsubsection{Current Pattern and Situation of Global IM Industry}

At present, what is the current pattern and status of intelligent manufacturing in the global manufacturing industry? The "New manufacturing" that promotes productivity and economic growth with a new generation of science and technology is a new pattern of global manufacturing in the global competition.

Developed countries have leading advantages in the middle- and high-end manufacturing fields. In the meantime, the widespread application of intelligent manufacturing technologies and mechanical equipment, such as industrial robots and automated production, has led to a significant decline in the total cost of manufacturing in the mid-to-high end industries. Therefore, it appeared to be a circumfluence phenomenon that the manufacturing industry has been transferred back to developed countries. Taking the comparison of labor costs in China and the United States, the research of the Oxford Economic Research Institute showed that the salary growth of China manufacturing labor 
force was significantly higher than its growth of production efficiency. Furthermore, the impact of Renminbi appreciation has continued to narrow the labor costs gap between China and the United States in the next five to ten years (Huiwen, 2016). Moreover, developing countries and emerging economies are actively attracting resource transfer of labor-intensive industries. Labor cost advantages in some countries such as India, Philippines, Brazil and Mexico, have no longer in osteffective positions. With lower manpower and resource costs, low-end manufacturing industries and assets are moving from China to these countries (Huiwen, 2016).

Under this circumstance, how can China manufacturing industry maintain its competitiveness to deal with these challenges? The implementation of 'Made in China 2025' was first proposed in the China Government Work Report in 2015. Premier Li claimed that China would insist on developing an innovation-driven economy, which involves the intelligent transformation to accelerate the national industrial transition from a volume manufacturing the power to a value manufacturing power (Keqiang, 2017). The minister of the Ministry of Industrial and Information Technology, Mr. Miao (2017) pointed out this national strategy aims to deepen reform and opening-up strategy, and continue to attract advanced technology and experiences from all countries, which will maintain a two-way open policy on the import of high-end industries and the transfer of low-end industries. Meanwhile, in order to achieve the transformation and upgrading of the manufacturing industry, the government encourages local enterprises to be adaptive in terms of the rapid development in industrialization and information technology.

Based on the current status and trends of global manufacturing development, Chinese manufacturing companies need to accelerate the development of Intelligent Manufacturing to enhance marketing competitiveness and fulfill customer requirements. According to the statistics from the Ministry of Industrial and Information Technology, the proportion of Chinese manufacturing output value has accounted for $33 \%$ of the global total in 2017, which is about $\$ 4.5$ trillion (Shen, 2018). In the same year, the output value of the China Intelligent Manufacturing industry reached 1500 billion RMB. For such a large economy, what is the current stage of its intelligent manufacturing development?

\subsubsection{Current Stage, Future Opportunities and Trends of China IM Development}

For decades, in the field of intelligent manufacturing, several theories have emerged and have played a positive role in guiding technology upgrades. However, there is always a lack of uniform standards and paradigms. Several scholars from the Chinese Academy of Engineering and Tsinghua University, Zhou et al. (2018) stated that it is necessary to summarize the basic paradigms of intelligent manufacturing. They combined the characteristics of information technology and manufacturing to generalize intelligent manufacturing into three basic stages, as shown in Figure 3. 
- Firstly, digital manufacturing. Information technology is in the digital stage.

- Secondly, smart manufacturing. The Internet is widely used in the manufacturing industry.

- Lastly, the new-generation smart manufacturing. The integrated application of artificial intelligence, mobile Internet and industrial IoT makes information technology enter into a high intelligence stage.

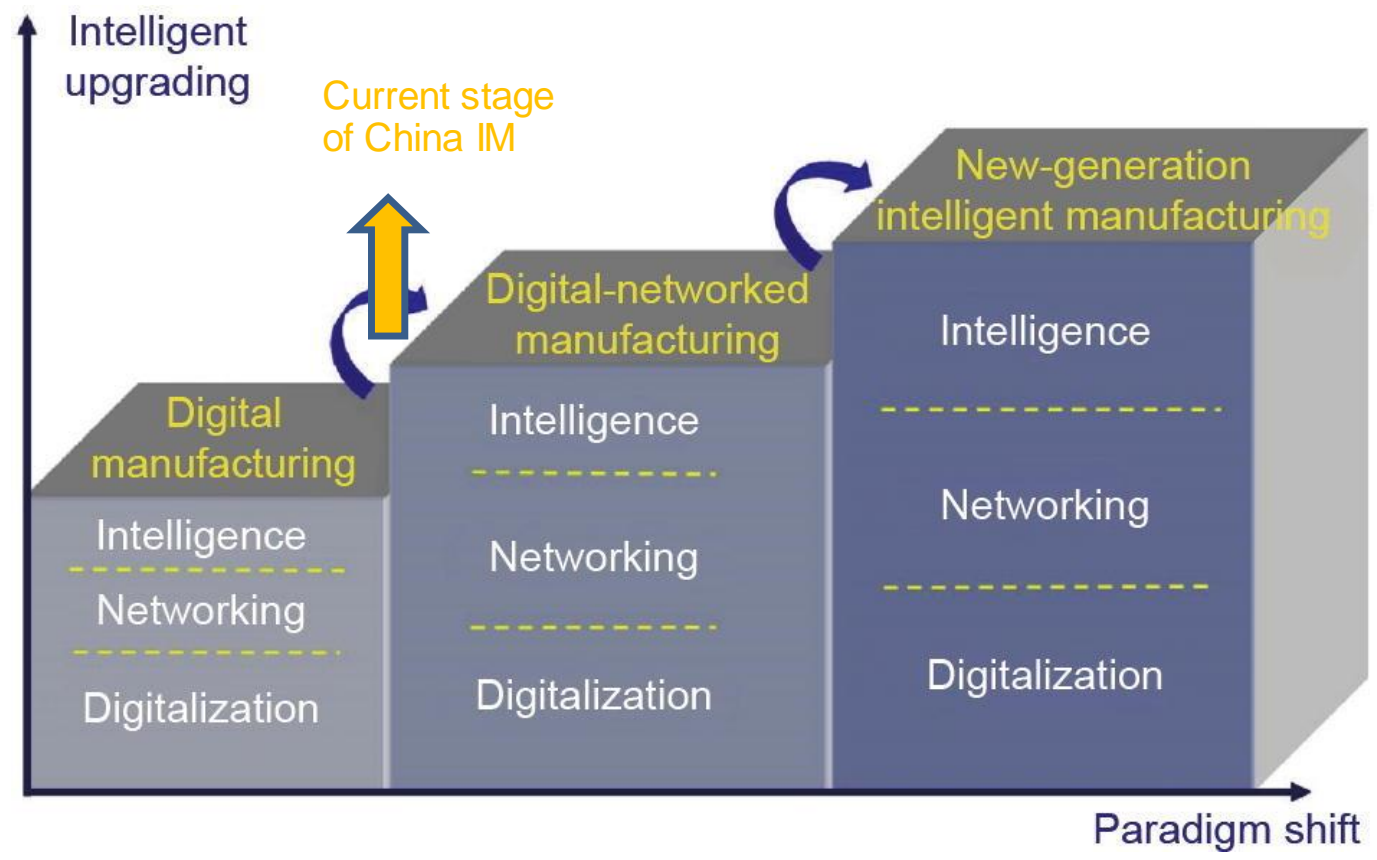

Figure 3. The evolution of three basic paradigms of IM (Zhou et al., 2018)

In addition, an analysis report of the intelligent manufacturing industry from Deloitte China was published in a famous financial magazine of China in 2018. The operation director Mr. Gao (2018) pointed out three key features of intelligent manufacturing. These features can also be used to understand the current stage of the development of China's manufacturing industry.

- The first feature is flexible manufacturing that is from large-scale mass production to large-scale personalized custom production.

- Secondly, it is decentration that is from centralized production to networked cross-regions collaborative production.

- The last one is an in-depth integration of information and industrialization. It is also called a physical factory + virtual factory.

Moreover, Mr. Gao Ting of Deloitte China, he conducted a study on 156 China manufacturing companies in 2017 (Gao, 2018). On the one hand, the results of the research indicated that Chinese manufacturing companies generally agreed with the importance of intelligent manufacturing, but have not yet formed a clear strategy. It has $89 \%$ of respondents who agreed that industrial IoT is crucial to enterprises' success in the next five years, and $72 \%$ of companies are already using it, but 
only $46 \%$ of companies have developed clearer IoT strategies and plans. On the other hand, the research found those manufacturing companies are still in the early stages of data application, and it will take time to conduct post-analysis to pre-judgment. The respondents are still in the perception phase of data application rather than the action stage. Most companies use the collected data to explain the regularity and root cause of historical performance, rather than using the data for predictive analysis to support decision-making.

Regarding the above analys is and researches, the overall level of intelligent manufacturing in China is between the first and second stages, and there is still a certain distance from the third phase. At present, the Chinese government is actively working towards their established goals, continuously implementing more intelligent manufacturing pilot demonstration projects, and accelerating the intelligent development of China manufacturing enterprises. As pointed out by the Minister of Industrial and Information Technology in the government report (Miao, 2017), the challenge and opportunity for China's smart manufacturing development in the future is to continue to compete with developed countries in high-end manufacturing fields such as rail transit and power equipment.

\subsection{LQ2: What is the Current Situation of the Local Valve Industry and its Development?}

Valves are key components of fluid-control systems and are used in a wide variety of fluid-control industries. It includes oil, gas, power, chemical, metallurgical and pharmaceutical manufacturing. Thus, it can be seen that the development of the valve industry is closely related to the macroeconomy.

According to the research report of global industrial valve market share in 2017 from China industry research consulting, it indicated that (see Table 1) Emerson Electric has only $2.94 \%$ of the global market share, and the top eight enterprises of valve industry only have $10.19 \%$ market share in total. Obviously, the competitive landscape of the global valve industry was more dispersed. The world's largest market research store, 'Research and Markets', indicated that some renowned valve manufacturers had shifted their production centers from developed countries to developing countries to reduce costs, such as China, India, and South Korea. 
Market Competition of Global Valve Industry (2017)

\begin{tabular}{ccccc}
\hline Ranking & Company & Country & Income (BillionS) & Market Share \\
\hline $\mathbf{1}$ & EmersonElectric & USA & 2.668 & $2.94 \%$ \\
$\mathbf{2}$ & IMIplc & UK & 1.482 & $1.63 \%$ \\
$\mathbf{3}$ & Flowserve & USA & 1.188 & $1.31 \%$ \\
$\mathbf{4}$ & CraneCompany & UK & 1.042 & $1.15 \%$ \\
$\mathbf{5}$ & Rotork & UK & 0.881 & $0.97 \%$ \\
$\mathbf{6}$ & Kitz & Japan & 0.838 & $0.92 \%$ \\
$\mathbf{7}$ & Metso & USA & 0.742 & $0.82 \%$ \\
$\mathbf{8}$ & KSB & Germany & 0.395 & $0.44 \%$ \\
\hline
\end{tabular}

Table 1. Market Competition of Global Valve Industry

\subsubsection{Current Situation of China Local Valve Industry}

As one of the largest valve manufacturing centers in the world, China has more than 3,000 valve manufacturers currently. Zhejiang and Jiangsu provinces are the largest and leading pump and valve manufacturing base and sales center in China. According to an industry research report of ZhiYan Consulting, there are 26 valve companies trading in Shenzhen, Shanghai, Hong Kong and New OTC markets in China (refer to Table 2). However, Chinese valve manufacturers are small, less than 500 companies with annual sales exceeding 20 million RMB. According to the 2017 research report, it indicated that China has only 17 valve companies whose annual sales revenues exceed 1 billion RMB. All of these showed that the current status of Chinese valve manufacture rs is small, scattered and its degree of concentration is very low. 
Market Competition of China Valve Industry (2017)

\begin{tabular}{|c|c|c|c|c|c|}
\hline Ranking & Company & $\begin{array}{c}\text { English } \\
\text { Name } \\
\end{array}$ & $\begin{array}{c}\text { Income } \\
\text { (Million RMB) } \\
\end{array}$ & $\begin{array}{c}\text { Net Profit } \\
\text { (Million RMB) }\end{array}$ & $\begin{array}{c}\text { Market Share } \\
(\%) \\
\end{array}$ \\
\hline 1 & 纽威股份 & Neway & 2365.8717 & 209.1773 & 16.66 \\
\hline 2 & 中核科技 & CNNC SF & 866.5018 & 44.5609 & 6.1 \\
\hline 3 & 道森股份 & DouSon & 826.7269 & 29.2346 & 5.82 \\
\hline 4 & 江苏神通 & JiangSu ShenTong & 745.6254 & 62.3996 & 5.25 \\
\hline 5 & 万讯自控 & Maxonic & 544.3763 & 44.365 & 3.83 \\
\hline 6 & 永和智控 & Yorhe & 543.2018 & 58.0284 & 3.83 \\
\hline 7 & 铜都润门 & TD Flow & 315.5029 & 32.3899 & 2.22 \\
\hline 8 & 川仪股份 & CQCY & 306.7507 & 30.67507 & 2.16 \\
\hline 9 & 浙江力诺 & Linuovalve & 298.2969 & 31.5427 & 2.1 \\
\hline 10 & 川力智能 & SCCLZN & 281.5824 & 14.4369 & 1.51 \\
\hline 11 & 上润股份 & Shangfa Valve & 239.2946 & 8.3662 & 1.69 \\
\hline 12 & 永盛科技 & Ysmeter & 213.8213 & 14.4369 & 1.51 \\
\hline 13 & 中德科技 & Zd-auto & 190.9942 & 10.7541 & 1.51 \\
\hline 14 & 金贸流体 & Jinmao foundry & 168.1964 & 11.4916 & 1.18 \\
\hline 15 & 德维股份 & DHV foundry & 157.4667 & 4.6192 & 1.11 \\
\hline 16 & 中寰股份 & Zh-flow & 122.0236 & 21.4691 & 0.86 \\
\hline 17 & 天海流体 & Sinopipevalve & 107.1321 & 17.559 & 0.75 \\
\hline 18 & 八叶科技 & Buyer-tech & 98.4827 & -8.7566 & 0.69 \\
\hline 19 & 南方泪门 & Nfvalve & 92.3145 & -14.6154 & 0.65 \\
\hline 20 & 耐特阀门 & Naitevalve & 60.6036 & 8.0628 & 0.43 \\
\hline 21 & 澎瀚机械 & Cnpenghan & 60.2733 & 10.3754 & 0.42 \\
\hline 22 & 固特科技 & Gutejixie & 43.6737 & 6.2112 & 0.31 \\
\hline 23 & 呼阀控股 & HUFA & 42.6654 & 2.4475 & 0.3 \\
\hline 24 & 格朗富 & Galumph & 24.5445 & 2.8498 & 0.17 \\
\hline 25 & 国电阀门 & GDFM & 24.1339 & -0.255 & 0.17 \\
\hline 26 & 汉德股份 & Wuhan Handvalve & 9.2125 & -2.042 & 0.06 \\
\hline
\end{tabular}

Table 2. Market Competition of China Local Valve Industry

In 2018, the recovery of the oil industry had led to a sharp rise in demand for petroleum equipment. Thereupon, the global valve market is in urgent need of suppliers with low prices and shorter delivery times. Due to the delivery time of Chinese valves is around 6 to 8 weeks, while the delivery time of European valves is as long as 6 to 24 weeks. Therefore, it is further promoted the expansion of China valve products in overseas markets.

\subsubsection{Difficulties and Challenges of China Local Valve Industry}

Although China's local valve industry has the advantage of price and delivery period, there are also some disadvantages. China is not only one of the largest valve exporters in the world but also imports a large number of mid- to high-end valves every year. The reason is the overall technical level of Chinese valve products is still behind developed countries, which has led to being dependent on imports to meet high-end demand. According to the National Bureau of Statistics, 
China's valve imports in 2017 reached 6.1 billion US dollars (National Bureau of Statistics of China, 2017).

China Forward-looking Industry Research Institute released a study in 2018, which indicated that the current status and challenges of China's local valve industry as follows.

- Low industry concentration, lack of world-renowned brands and large multinational companies

- Unreasonable industrial structure, concentrated in the low-end market, lack of high-end research and development

- Industry standardization is not perfect, independent innovation ability and product quality are behind of developed countries.

In conclusion, through the above analysis of the current situation, difficulties and challenges of the Chinese valve industry, it can be seen that its future development opportunities and development direction is to increase international competitiveness through developing its technical capability and flexible manufacturing capacity of high-end valve products.

Based on the study of LQ1, China has continuously introduced a series of new policies and guidelines of intelligent manufacturing in recent years, which is exactly suitable for solving the needs of China's local valve industry to improve production efficiency and product quality. Intelligent manufacturing can effectively shorten the valve development cycle, improve production efficiency and product quality, reduce operating costs, resources and energy consumption. The development of intelligent manufacturing will undoubtedly become the guiding direction of valve industry development.

\subsection{LQ3: What is the Current Status of IM in China's Local Valve Industry?}

As most fluid materials need construction projects to transport, the valve industry is one of the most important suppliers to the construction projects and the sustainable development of the valve industry can affect the built environment. With intelligent management, the consumption and waste of resources can be reduced, the production cost can be minimized and the customized products can be designed more efficiently, which may improve the competitive ability of the enterprises and contribute to the sustainable built environment. (Miranda et al, 2019). According to Wong and Li (2009), 'self-diagnostic of operation deviations', 'adaptive limiting control algorithm', and 'yearround time schedule performance' are the three top intelligence indicators in the intelligent management. 
Since China government released "Made in China 2025" and set intelligent manufacturing as the main direction. The valve industry is also actively promoting smart manufacturing. In 2015, the Ministry of Industrial and Information Technology (MIIT) continued to implement the integration of informatization and industrialization. The MIIT organized the selection of pilot enterprises to further accelerate the deep integration of the new generation of information technology and manufacturing (Tian, 2017).

Many valve manufacturers have active responded and supported the national encouragement policies, once the manufacturers have obtained the evaluation certificate of III management system which is issued by the MIIT, they could receive funds support up to 80 thousand RMB from the government. We found some valve manufacturers have received this certificate and award through the MIIT official website. Some other valve enterprises have begun to apply for this evaluation certificate.

On July 22, 2016, Jiangsu Shentong Valve was awarded the certificate.

On May 24, 2017, Suzhou Neway Valve was awarded the certificate.

On July 28, 2017, the Jiangsu Yiwu Valve group was awarded the certificate.

According to the Economic and Information Committee of Jiangsu Province on January 17, 2017, the list of demonstration smart workshops in Jiangsu Province was announced. It included the smart production workshop of the ball valve of Newway Valve Company, which is ranked first in the valve industry. In May 2018, the first "Green Intelligent High-end Valve Production Line" project of Fujian Datong Mutual Group was officially launched. This production line was jointly built with the Italian IMF (Emford) Group which is the global top one casting equipment supplier (Wen, 2018).

Although China valve manufacturers are all planning and promoting the transformation of intelligent manufacturing like a raging fire, due to the low concentration of the overall industry and no international leader, those companies are developing their own smart manufacturing based on their own understanding and strategy. In order to fully understand the research status of China's local valve industry in the field of intelligent manufacturing, the author uses the literature search method to search from the core journals of CNKIand Google Scholars with the keywords of 'Intelligent manufacturing' and 'Valve'. It was found that there was a large amount of research literature on 'Intelligent Manufacturing' that is sufficient to show the vitality of this research field. But there are few documents of intelligent manufacturing in the valve industry, and there is a lack of mature models and effective summary. 


\subsection{Summary}

The literature review above provides an answer to all three LQs. The answer to LQ1 is that intelligent manufacturing development level of China is between the first and second stages, China needs to take advantage of this opportunity to promote its intelligent manufacturing to get rid of the current manufacturing industry is a big but not strong predicament. The answer to LQ2 is that the Chinese government's national strategy of developing intelligent manufacturing is just the right prescription and direction to solve the current difficulties in China's local valve industry. The answer to LQ3 is that China valve manufacturers have a comprehensive consensus on implementing smart manufacturing, but so far, they all adopt their own development approach, and their methods and planning directions are different. This also intensifies the dispersion of the industry and is not conducive to building international brands and enterprises.

Therefore, based on the above literature review, the author will focus on two research questions below.

RQ1: What is the degree of maturity of intelligent manufacturing capability in China's local valve industry?

RQ2: What is the feasible approach for China valve manufacturers to develop intelligent manufacturing? 


\section{Research Methods}

The purpose of this section is to provide the details of the methodology for studying two RQs. It included a research strategy and how to answer two RQs, through adopted research methods to design research for analyzing two RQs. The research limitations of the study will be discussed at the end.

\subsection{Research Design and Theory}

Through the analysis of the literature review, the conclusion is that the main direction of China manufacturing strategic transformation and upgrading is to develop intelligent manufacturing, and its current IM level is still between the first stage and the second stage. However, the process of digitalization of the Chinese Valve manufacturing industry has started relatively late. Although all organizations of the valve industry have the strategic consensus, because of the overall industry is relatively scattered, everyone is exploring their own development approach. Under these circumstances, not only the overall level of the industry is low, but also all necessary resources of all aspects cannot be applied reasonably and effectively. Whenever the people knew 'what I am going to do', the next step is going to find an answer to 'where are we' and 'how to do it'.

The researchers tend to base on mixed-method to collection and analysis investigation data to best understand research questions. It employs the strategies that are data collection from both numeric information of online survey by the quantitative method and text information of interview and case study by the qualitative method.

In order to examine the local valve industry, an online survey would be employed to inquiry and evaluate the current average maturity of IM in the valve industry quantitatively. Moreover, the researcher planned to interview some senior employees of different valve companies to gain a deep understanding of their concept of IM development strategy through semi-structured interviews and case studies. Talking with interviewees can be valuable and validated through the real sharing process because they have rich practical experiences and learnings (Adler et al.,1995).

Firstly, an online survey would be conducted to study China's local valve manufacturers in order to understand the development status of this industry and the maturity of its intelligent manufacturing. As well as the solutions currently in use and future development strategies of them. This can be used to analyze whether the industry has mature, intelligent manufacturing models and effective industry solutions.

Secondly, through interviews and case study methods, the author will conduct analysis with typical representative local valve companies. According to their rich experience in the industry to combine 
with the development of intelligent technology, the purpose of the interview is to analyze the feasible future approach of intelligent development in this field and to identify the direction for valve organizations.

Finally, the maturity of the valve industry was determined by quantitative methods, and then some typical valve companies were studied in two qualitative ways (Adler et al,1995). This strategy is the process of advancing the research on the target layer by layer and gradually explore the feasible approaches to the development of intelligent manufacturing. The three specific research methods will be described one by one in the following paragraph.

\subsection{Research Design}

According to the literature review, China's local valve industry is relatively scattered, and its production process is extremely complicated. There are many complicated processes such as casting, forging, machining, heat treatment, painting, assembly and so on. Considering achieving smart manufacturing management, all organizations have to face big challenges. Although some organizations have started to plan or completed a few parts of their intelligent manufacturing, they have not formed an effective system. Moreover, what is their maturity level of intelligent manufacturing and how they will develop in the future are the next directions that need to be analyzed and studied. Therefore, the next step of this research methodology is to investigate some representative organizations in the industry through surveys and interviews, to know their current status, business needs and future development goals.

\subsubsection{Online Survey}

In order to answer RQ1, the authors used the survey method to investigate the intelligent manufacturing of China valve organizations. Due to the use of an online questionnaire, a large number of sample populations can be reached, and data collection is also faster than other methods. The target of this survey is to analyze the current status of China's local valve industry, their current maturity of intelligence manufacturing, their needs of intelligent development, and their challenges and vision of further business development. Then, combined with the results of the survey data, to analyze whether the Chinese local valve industry has mature, intelligent manufacturing models and effective industry solutions.

The survey was designed and distributed through Sojump that is the earliest and largest online survey service in China. Since the respondents need to be restricted to practitioners of the Chinese valve manufacturing industry, they will be asked to confirm their industry and working department at the 
beginning of this survey. In order to avoid interference to affect the accuracy of investigation data, the survey has set up automatic rejection if someone was not employed in this industry.

As mentioned above, Jiangsu Province and Zhejiang Province are the largest manufacturing base and sales center of pump valves in China, including $70 \%$ of the top 15 companies in China's local valve industry. Therefore, this survey will focus on valve companies in these two provinces. Since the author has worked in the IT department of the top 15 valve companies, she has a certain understanding of information technology development in this industry. Through her working relationships, there are many direct practitioners in the valve industry or professional suppliers with information system solutions in the industry. Therefore, the scope of this investigation can involve many well-known valve companies in China.

The content of the survey does not involve any trade secrets and core data of any business. At the beginning of the survey, respondents would be informed that the survey is voluntary and would not collect any private user information or trade secrets. General research ethics and appropriate political norms were followed in the design and distribution of surveys.

Because the overall proportion of the valve industry in China's manufacturing system is small, the number of regular valve organizations that can reach a certain scale and have a standardized management system is even more limited. Therefore, the target of the investigation is set to 100 responses to obtain an effective statistical result under this premise. The designed questions of the survey are intended to provide data for directly applicable to answering RQ1. The survey was designed to have a total of 21 questions to answer RQ1 and RQ2, the data collected from the survey was used to investigate the current state of valve companies by employing the intelligent manufacturing capability maturity model issued by the Ministry of Industrial and Information Technology of China (Tian, 2017). For some diversified questions of the survey, which could also be applicable to study RQ2, those will provide a direct or indirect information basis for qualitative analysis of RQ2.

In addition, further interviews will be conducted to analyze and study the contents that may not be answered accurately and clearly in this survey. Through some face-to-face interviews with representative employees of the valve industry, the purpose is to understand the development status and challenges of the industry or companies and to analyze the development approach of intelligent manufacturing suitable for the industry. 


\subsubsection{Interviews and Case Study}

Since the development path of intelligent manufacturing is not a quantifiable concept, all industries have their own particularities, so it is even more impossible to identify them by voting. It is needed to combine the actual status and needs of the industry development to make a suitable development approach. Therefore, it needs to be studied by qualitative analysis.

In order to answer RQ2 and three relevant hypotheses, the author interviewed some key employees of the top 15 valve companies through the interview method. The follow-up interview after the survey is carried out to further investigate the development approach of intelligent manufacturing. The interviewees are divided into three types of enterprise personnel. They are enterprise operation management (decision-makers), production workshop management (field execution level) and information technology experts (system management level).

Based on the components of intelligent manufacturing, it links to the small and complicated limitations of the valve industry and current situation of frequent changes in demand and then combines the current level of intelligent maturity of valve companies to design interview questions. Through interviews with people from three perspectives, the designed questions are going to verify whether three hypotheses are established from three aspects of the current assessment, capacity evaluation and demand analysis.

Through the interviews based on the above aspects, the author will collect all feedbacks from interviewees of those representative companies and combine their rich industry experiences to do two case studies for researching a unique intelligent manufacturing development path suitable for them.

\subsection{Summary}

The research methods used in this section include survey, interview and case study methods. All questions were designed to answer two research questions and figure out a development approach to intelligent manufacturing in the valve industry. 


\section{Results}

This section is aimed to provide detail results of the online survey and interviews for studying two RQs. The major findings of survey results will be conducted to answer RQ1. In terms of some hypotheses of RQ2 are not applicable to deduce through the online survey, so that will be further researched by interview and cast study way. The major findings of interviews with several typical representative valve practitioners will provide more clear practices and experiences of the current situation, as well as guide future landscape of China's local valve industry.

\subsection{Survey Study}

This online survey of intelligent manufacturing development in China's local valve industry was mainly designed to answer RQ1. Since May 2, 2019, the survey received 124 respondents in total through Sojump online questionnaire platform. 114 responses are valid and they answered all the questionnaire questions. Further analysis will focus on the data from these 114 fully answered surveys. As mentioned earlier, this survey will be conducted and focused on the Yangtze River Delta region, which is the most developed region in China. As is shown in Figure 4, the survey collected 55.26\% of results were from Jiangsu Province, and the top two China local valve manufacturers are located in Jiangsu Province as well. Obviously, this shows that Jiangsu Province is the main player in China's local valve industry.

\section{Survey Sources Analysis by China Geographical Distribution}

\begin{tabular}{|c|c|c|c|}
\hline Province & Qty & Percentage & Oversea \\
\hline JiangSu & 63 & $55.26 \%$ & Beiling \\
\hline Anhui & 18 & $15.79 \%$ & ZheJiang \\
\hline Shanghai & 12 & $10.53 \%$ & $\begin{array}{c}\text { Tianjin } \\
\text { Shanghai }\end{array}$ \\
\hline Zhejiang & 10 & $8.77 \%$ & JiangSu \\
\hline BeiJing & 4 & $3.51 \%$ & Anhui \\
\hline TianJin & 2 & $1.75 \%$ & $15.79 \%$ \\
\hline Oversea & 5 & $4.39 \%$ & \\
\hline
\end{tabular}

Figure 4. Analysis of Geographical Distribution of the Survey Sources

According to intelligent manufacturing development is the main direction of China's local valve industry (see Table 3), 35.09\% of the respondents strongly agreed with this opinion. Another $41.23 \%$ 
of the respondents agreed with it. In total, $76.32 \%$ of all respondents agreed with promoting intelligent manufacturing that is the future of the valve industry.

\begin{tabular}{|l|c|c|}
\hline \multicolumn{1}{|c|}{ Options } & Sum & Percentage \\
\hline 0 - Strong disagreed & 5 & $4.39 \%$ \\
\hline 1 - Disagreed & 2 & $1.75 \%$ \\
\hline 2 - Neither agree nor disagree & 20 & $17.54 \%$ \\
\hline 3 - Agreed & 47 & $41.23 \%$ \\
\hline 4 - Strong agreed & 40 & $35.09 \%$ \\
\hline Valid survey quantity & 114 & \\
\hline
\end{tabular}

Table 3. Analysis of Respondents' Opinions of Implement Intelligent Manufacturing

Regarding the current situation of intelligent manufacturing development in all investigated companies, the survey results indicated that only $15.79 \%$ of the companies have to execute partial intelligent manufacturing. Another $43.86 \%$ of the companies have started to plan this strategy. However, $35.09 \%$ of the companies only have an idea to implement intelligent manufacturing; even $5.26 \%$ of the companies do not plan to do it (see Table 4).

\begin{tabular}{|l|c|c|}
\hline \multicolumn{1}{|c|}{ Options } & Sum & Percentage \\
\hline 0 - Unplanned & 6 & $5.26 \%$ \\
\hline 1 - Only has idea & 40 & $35.09 \%$ \\
\hline 2 - Start to plan & 50 & $43.86 \%$ \\
\hline 3 - Executing & 18 & $15.79 \%$ \\
\hline 4 - Completed & 0 & $0 \%$ \\
\hline Valid survey quantity & 114 & \\
\hline
\end{tabular}

Table 4. Analysis Current Status of Executing or Planning IM in China Valve

After the quantitative analysis of the original survey results in terms of geography, industry type and strategic development direction, next is analysis of the maturity of current intelligent manufacturing development in China's local valve industry.

Firstly, the Ministry of Industry and Information Technology has defined two dimensions of smart manufacturing maturity in its white paper (Tian, 2017), which are intelligence and manufacturing. 
Based on these two dimensions, the white paper also defined several measurable indicators. The 12 questions in this survey were designed to answer RQ1.

Next, to analyze the survey results by SPSS, which is a widely regarded statistical analysis software. Table 5 shows the maturity score and corresponding level, which was defined in the White Paper of MIIT.

\begin{tabular}{|c|c|c|}
\hline \multicolumn{2}{|c|}{ Table of Scores and Maturity Level } \\
\hline Maturity level & Value & Criteria of Evaluation \\
\hline 0 - No planning level & 1 & $<0.8$ \\
\hline 1 - Planning level & 2 & $0.8 \leq \mathrm{X}<1.8$ \\
\hline 2 - Standardization level & 3 & $1.8 \leq \mathrm{X}<2.8$ \\
\hline 3 - Integration level & 4 & $2.8 \leq \mathrm{X}<3.8$ \\
\hline 4 - Optimizing level & 5 & $3.8 \leq \mathrm{X}<4.8$ \\
\hline 5 - Leading level & 6 & $4.8 \leq \mathrm{X} \leq 5$ \\
\hline
\end{tabular}

Table 5. Scores and Maturity Level from MIIT

According to the above, a reference table (Table 6) was used to analyze collected data by using the T-test quantitative analysis method. The analysis results of 12 capabilities showed that the P-values showing significant and are all less than 0.001. Obviously, the Mean value of these 12 capabilities is staying around 2 up and down. Therefore, the data of Table 6 indicated the maturity level of these 114 surveys is basically standing at the 'Planning' level. As well as it has proved the answer to RQ1.

\begin{tabular}{|c|l|c|c|c|c|c|c|c|}
\hline \multicolumn{7}{|c|}{ Single Sample T test results } \\
\hline IM Capability level & $\begin{array}{c}\text { Sample } \\
\text { Size }\end{array}$ & Min. & Max. & Mean & $\begin{array}{c}\text { Std. } \\
\text { deviation }\end{array}$ & t & p \\
\hline 1 & Product and Process design & 114 & 1 & 6 & 2.096 & 0.892 & 15.516 & $0.000^{* *}$ \\
\hline 2 & Production & 114 & 1 & 5 & 2.088 & 0.771 & 17.839 & $0.000^{* *}$ \\
\hline 3 & Warehousing and Logistics & 114 & 1 & 5 & 2.035 & 0.786 & 16.772 & $0.000^{* *}$ \\
\hline 4 & Planning and Scheduling & 114 & 1 & 5 & 2.009 & 0.758 & 17.018 & $0.000^{* *}$ \\
\hline 5 & Sales and Service & 114 & 1 & 5 & 2.009 & 0.804 & 16.058 & $0.000^{* *}$ \\
\hline 6 & Quality Control & 114 & 1 & 5 & 2.026 & 0.792 & 16.527 & $0.000^{* *}$ \\
\hline 7 & Safety and Environment & 114 & 1 & 6 & 2.009 & 0.936 & 13.789 & $0.000^{* *}$ \\
\hline 8 & Resources & 114 & 1 & 5 & 2.018 & 0.764 & 17.015 & $0.000^{* *}$ \\
\hline 9 & Interaction and Connectivity & 114 & 1 & 5 & 1.956 & 0.824 & 14.975 & $0.000^{* *}$ \\
\hline 10 & System Integration & 114 & 1 & 5 & 2.202 & 0.843 & 17.748 & $0.000^{* *}$ \\
\hline 11 & Information Integration & 114 & 1 & 5 & 2.123 & 0.904 & 15.629 & $0.000^{* *}$ \\
\hline 12 & Emerging Business & 114 & 1 & 5 & 1.904 & 0.74 & 15.914 & $0.000^{* *}$ \\
\hline & $*$ p $<0.05 * *$ p $<0.01$ & & & & & & & \\
\hline
\end{tabular}

Table 6. Single Sample T-Test of China Valve IM Development Survey 
In addition, the survey results also verified the author's opinion of LQ3 in the literature review, which is China's local valve manufacturing industry has a comprehensive consensus on the development of intelligent manufacturing, but the overall maturity level in the current situation is still in the planning stage.

\subsection{Interview Study}

The author investigated some employees from China local valve companies via phone calls or interviews in order to answer RQ2. As a qualitative analysis, the aim of the interview study is to identify what is feasible development approach of intelligent manufacturing in China's local valve industry. In total, the dissertation has conducted 6 interviews with 3 in the form of face-to-face and another 3 via phone calls. All interviewee and their general backgrounds are listed in the following table 7 .

\begin{tabular}{clcc}
\hline Participant & \multicolumn{1}{c}{ Position } & Interview date & $\begin{array}{c}\text { Years of service in } \\
\text { local valve industry }\end{array}$ \\
\hline R1 & General Manager & 10 Mar. 2019 & 18 years \\
R2 & Production Director & 19 Apr. 2019 & 22 years \\
R3 & Sr. IT Manager & 26 Apr. 2019 & 3 years \\
R4 & R\&D Manager & 26 Apr. 2019 & 8 years \\
R5 & Workshop Leader & 6 May. 2019 & 16 years \\
R6 & Supply Chain Director & 6 May. 2019 & 14 years \\
\hline
\end{tabular}

Table 7. Descriptive Information of Interview Participants

According to RQ2, the author has three hypotheses of the development approach. Therefore, the content of the interview was built around these three hypotheses.

\section{H1: Smart devices are the foundation of intelligent manufacturing development.}

Respondents agreed that the valve market has a lot of room for development and the competition is fierce. Due to the irrational industrial structure, backward industrial management level, and weak independent innovation capability, China's local valve industry lacks world-renowned brands and multinational companies. If the valve industry wants to rise and transform, it must upgrade from lowend processing to high-quality customized manufacturing.

One point raised by R1 (GM), he thought that customer-centricity means meeting individual needs and flexible production. From customer order to product design, production and logistics and other processes for accurate and efficient management, all through intelligent devices and real-time data 
can be achieved. According to R3 (Sr. IT), she commented that the goal of intelligent manufacturing is to enable smart devices to drive production, to complete smart products that customers need, and to link product business processes through big data to improve product quality, production efficie ncy and cost reduction. However, the basis of data collection is to invest intelligent equipment for production management. According to R6 (SC director), to develop and manufacture a sophisticated product, it is bound to require lean production and high-precision automated processing equipment. The premise of intelligent manufacturing is to collect real-time production data and then drive the next step of execution through big data analysis. The R2 (Production director) gave his comments from another perspective, his foundry factory facing a serious challenge because it is hard to find some smart devices to casting his product. All the above opinions were relevant to hypothesis 1 (refer to Table 8).

\begin{tabular}{|c|c|c|c|}
\hline Example insights & First-order concepts & Link to the hypothese & Layers \\
\hline $\begin{array}{l}\text { "The international development path of Chinese local valve enterprises must } \\
\text { rely on intelligent information technology to implement a series of intelligent } \\
\text { management such as R\&D, production, quality, warehousing, etc. This is } \\
\text { like building a sophisticated nervous system, which is the neuron of the } \\
\text { whole system. And is also the most important foundation." (RI) }\end{array}$ & $\begin{array}{l}\text { IM is the strategic } \\
\text { direction; } \\
\text { Smart devices are core } \\
\text { fundation; }\end{array}$ & $\begin{array}{l}\text { H1: } \\
\text { Smart devices is the } \\
\text { foundation of intelligent } \\
\text { manufacturing development. }\end{array}$ & $\begin{array}{l}\text { 1st Tier: } \\
\text { Smart Device }\end{array}$ \\
\hline $\begin{array}{l}\text { The goal of intelligent mamufacturing is to enable smart devices to drive } \\
\text { production, complete customer-customized products, and drive the entire } \\
\text { business process through data inter action. (R3) }\end{array}$ & $\begin{array}{l}\text { Smart device is the } \\
\text { first driver }\end{array}$ & $\begin{array}{l}\text { H1: } \\
\text { Smart devices is the } \\
\text { foundation of intelligent } \\
\text { manufacturing development. }\end{array}$ & $\begin{array}{l}\text { 1st Tier: } \\
\text { Smart Device }\end{array}$ \\
\hline $\begin{array}{l}\text { The intelligent mamufacturing }=\text { Automation equipment }+ \text { Intelligent system } \\
\text { (RS) }\end{array}$ & $\begin{array}{l}\text { Smart devices are } \\
\text { indispensable } \\
\text { component }\end{array}$ & $\begin{array}{l}\text { H1: } \\
\text { Smart devices is the } \\
\text { foundation of intelligent } \\
\text { manufacturing development. }\end{array}$ & $\begin{array}{l}\text { 1st Tier: } \\
\text { Smart Device }\end{array}$ \\
\hline $\begin{array}{l}\text { Our foundry factory is very eager to achieve intelligent production, but in } \\
\text { terms of smart equipment currently available for casting is very scarce, so } \\
\text { our capacity and cost are serioushy affected. (R2) }\end{array}$ & $\begin{array}{l}\text { Lack smart device in } \\
\text { casting has a serious } \\
\text { impack on production }\end{array}$ & $\begin{array}{l}\text { H1: } \\
\text { Smart devices is the } \\
\text { foundation of intelligent } \\
\text { manufacturing development. }\end{array}$ & $\begin{array}{l}\text { 1st Tier: } \\
\text { Smart Device }\end{array}$ \\
\hline
\end{tabular}

Table 8. Interviewee's Opinion toward Relevant Hypotheses 1

In addition, the author shared with the respondents the survey results of the smart devices usage in 114 surveys (refer to Figure 5), it including $62.28 \%$ of the respondents' companies have adopted CNC machines, and intelligent sensing and control equipment has accounted for $42.11 \%$, and using smart detection equipment has accounted for $35.96 \%$. Afterward, the interviewees agreed with the survey results and also strongly agreed that smart devices are the basis of intelligent production. Right now, they have used various intelligent equipment in their companies, even planning to invest more. 


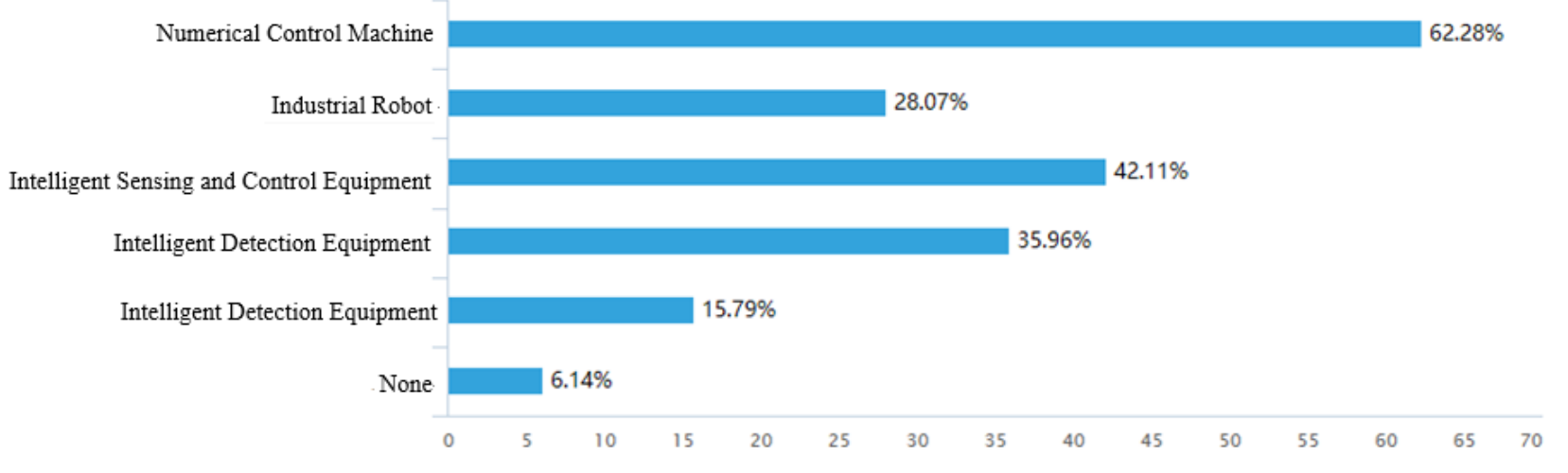

Figure 5. The Smart Devices Usage of the Interviewees' Companies

In summary, respondents commented if local valve manufacturing wants to become stronger, and high-precision equipment such as CNC machine tools, intelligent sensing and control equipment, industrial robots, and intelligent inspection equipment are the essential foundation.

\section{H2: Smart factories is the necessary way to achieve smart manufacturing strategy.}

After completing the basic construction of smart devices, what is the next? During the interviews, the author has focused on this topic to communicate with all interviewees.

According to R2 (Production Director), the valve industry has its own special industry characteristics. On the one hand, the valve products cover a wide range of products, covering all aspects of human life. This also means that its specifications and requirements vary greatly. Especially in the field of industrial valves, within different industrial scenes, valve products are largely customized according to customer needs. On the other hand, customer demand for multiple varieties and small quantities are always the biggest business challenge for valve companies. Therefore, in the past few years, the industry has been seeking solutions to meet the customized needs of the market, but also to achieve high-volume, modular, standardized, flexible production to control operating costs. However, intelligent manufacturing is the best way and solution for the global valve industry to solve this problem. The most important part of it is the smart factory.

As a GM, the R1 has such an interpretation of the IM development path. From the tactical level, they must explore firstly, then conduct a pilot. After that, they will start to promote one by one, and finally begin to universalize. From a strategic perspective, R1 thought there must have a master plan at first, then choose a key breakthrough, and then carry out step-by-step implementation. Finally, they begin to comprehensively promote the whole strategic plan. However, the key to this breakthrough is to build a smart factory. 
The R3 (Sr. IT) thought that the most important milestone in the development of intelligent manufacturing is to realize workshops and factories that can intelligently manage production. The ultimate goal of intelligent manufacturing is to provide high-end products that meet customer requirements, as well as the production of these products takes place in the workshop and factory. An intelligent production workshop directly determines the process, quality, cost, and production capacity and delivery date.

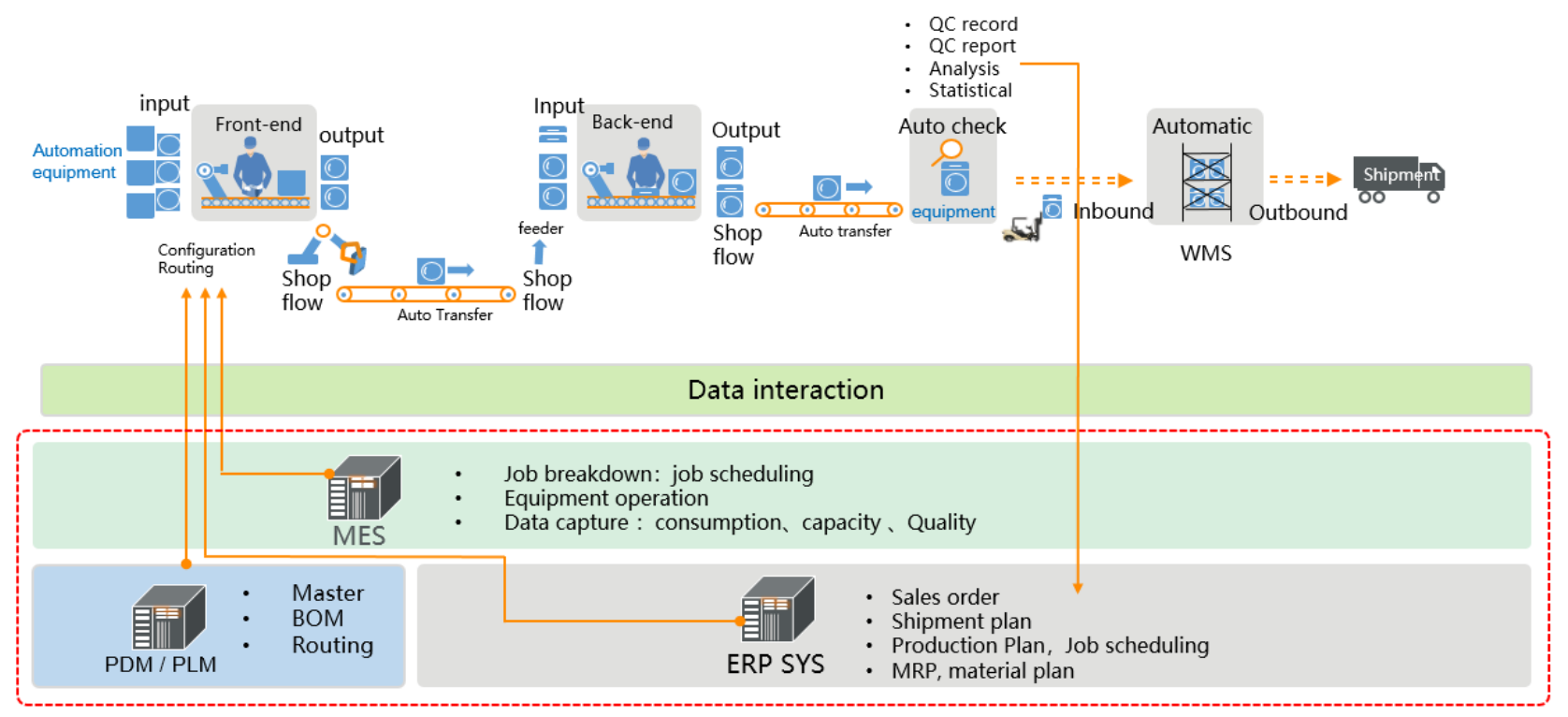

Figure 6. Smart Factory Landscape

Based on the physical basis of intelligent production equipment and sensing control equipment, to combine with a series of professional software composed of various information technology systems and management platforms (Figure 6)., such as ERP, PLM, CRM, WMS and MES. This realizes the interconnection environment of virtual and realistic scenes for intelligent workshops and factories. All the above opinions were relevant to hypothesis 2 (Table 9).

\begin{tabular}{|c|c|c|c|}
\hline Example insights & First-order concepts & Link to the hypothese & Layers \\
\hline $\begin{array}{l}\text { Understanding the development of intelligent mamfacturing from the } \\
\text { strategic and tactical point of view, and intelligent workshop and factory } \\
\text { is an important milestone and breakthrough.(RI) }\end{array}$ & $\begin{array}{l}\text { the key milestone and } \\
\text { breakthrough. }\end{array}$ & $\begin{array}{l}\mathrm{H} 2 \text { : } \\
\text { Smart factories is the } \\
\text { necessary way to achieve } \\
\text { smart manufacturing strategy }\end{array}$ & $\begin{array}{l}\text { 2nd Tier: } \\
\text { Management } \\
\text { and Execution }\end{array}$ \\
\hline $\begin{array}{l}\text { Flexible production with multiple categories, large quantities, } \\
\text { modularization and standardization is the future of local valve industry. } \\
\text { The smart factory is the most important part to realize this vision.(R2) }\end{array}$ & $\begin{array}{l}\text { the most important } \\
\text { part to realize the } \\
\text { business vision. }\end{array}$ & $\begin{array}{l}\mathrm{H} 2 \text { : } \\
\text { Smart factories is the } \\
\text { necessary way to achieve } \\
\text { smart manufacturing strategy }\end{array}$ & $\begin{array}{l}\text { 2nd Tier: } \\
\text { Management } \\
\text { and Execution }\end{array}$ \\
\hline $\begin{array}{l}\text { With intelligent equipment as the foundation, and combined with various } \\
\text { information technology management platforms, the interconnection of } \\
\text { virtual and reality scenes will eventually be realized, it creating a complete } \\
\text { hardware and software foumdation for the intelligent factory.(R3) }\end{array}$ & $\begin{array}{l}\text { a intelligent } \\
\text { environment that is } \\
\text { build on the hardware } \\
\text { and software } \\
\text { foundation }\end{array}$ & $\begin{array}{l}\mathrm{H} 2 \text { : } \\
\text { Smart factories is the } \\
\text { necessary way to achieve } \\
\text { smart manufacturing strategy }\end{array}$ & $\begin{array}{l}\text { 2nd Tier: } \\
\text { Management } \\
\text { and Execution }\end{array}$ \\
\hline
\end{tabular}


In summary, the opinions of the interviewees are smart devices and automated production line equipment is the foundation in the entire development architecture system. Then through the relevant information technology software and platform to build automated production lines and smart factories that are the core part of the whole architecture system, which is also the only way.

\section{H3: the future of intelligent manufacturing is to realize cross-regional integration and collaborative development among companies through Internet technology.}

The most difficult and core part of building a complete intelligent manufacturing system is to digitize the production process through build a smart factory. After this milestone, what is the next objective?

According to R6 (SC director), he pointed out using the Internet of Things technology to capture dynamic information and provide intelligent services to customers. The respondent R1 (GM) starts from the strategic level; he focuses on the multi-factory and cross-regional collaborative development through high-tech information network technology to maximize their value chain. The point raised of R4 (R\&D Director), he agreed that the best product service is to provide customers with sustainable technology and maintenance support. The remote service model across time and region will definitely expand the business model and brand recognition of their company. As an IT expert, R3 comments their company will plan to use the Internet of Things, cloud computing, big data and other technologies to collect, filter, analyze, store and manage data such as equipment status, operation and environmental conditions of smart products. Based on the analys is results of the above data, they are able to provide high-quality services such as daily operation and maintenance, predictive maintenance and warning, diagnosis and repair, operation optimization, and remote upgrade (refer to Table 10).

\begin{tabular}{|c|c|c|c|}
\hline Example insights & First-order concepts & Link to the hypothese & Layers \\
\hline $\begin{array}{l}\text { Realize cross-regional collaboration and integration development based } \\
\text { on smart device and information interaction. (RI) }\end{array}$ & $\begin{array}{l}\text { cross-regional } \\
\text { collaboration and } \\
\text { integration }\end{array}$ & $\begin{array}{l}\mathrm{H} 3 \text { : } \\
\text { realize cross-regional and } \\
\text { collaborative development } \\
\text { through Internet technology }\end{array}$ & $\begin{array}{l}\text { 3rd Tier: } \\
\text { network service }\end{array}$ \\
\hline $\begin{array}{l}\text { The king is realize resource sharing, intelligent management and service } \\
\text { under the support of a new generation of information technology. (R3) }\end{array}$ & $\begin{array}{l}\text { realize resource } \\
\text { sharing and high- } \\
\text { quailty service }\end{array}$ & $\begin{array}{l}\text { H3: } \\
\text { realize cross-regional and } \\
\text { collaborative development } \\
\text { through Internet technology }\end{array}$ & $\begin{array}{l}\text { 3rd Tier: } \\
\text { network service }\end{array}$ \\
\hline $\begin{array}{l}\text { The best product service is to provide customers with sustainable } \\
\text { technology and maintenance support. (R4) }\end{array}$ & $\begin{array}{l}\text { sustanable } \\
\text { technology and } \\
\text { remote support is the } \\
\text { best service }\end{array}$ & $\begin{array}{l}\text { H3: } \\
\text { realize cross-regional and } \\
\text { collaborative development } \\
\text { through Internet technology }\end{array}$ & $\begin{array}{l}\text { 3rd Tier: } \\
\text { network service }\end{array}$ \\
\hline $\begin{array}{l}\text { Using the Internet of Things technology to capture dynamic information } \\
\text { and provide intelligent services to customer's. (R6) }\end{array}$ & $\begin{array}{l}\text { capture data through } \\
\text { Io } T \text { and provide } \\
\text { intelligent service }\end{array}$ & $\begin{array}{l}\text { H3: } \\
\text { realize cross-regional and } \\
\text { collaborative development } \\
\text { through Internet technology }\end{array}$ & $\begin{array}{l}\text { 3rd Tier: } \\
\text { network service }\end{array}$ \\
\hline
\end{tabular}

Table 10. Interviewee's Opinion toward Relevant Hypotheses 3 
In summary, the opinions of the interviewee are using industrial Internet technology to achieve an intelligent remote service model, as well as cross-regional collaborative operations. It will promote the continued development of its value chain.

\subsection{Case Studies}

In order to further analyze and deduct RQ2, the author has collected more valuable data to prove RQ2 by investigating three case studies. These case studies of representative companies included Suzhou Neway Valve and DHV Valve Casting. These two companies are located in the Yangtze River Delta region, where one of the fastest development and strongest industrial regions in China. The companies of this region have complete coverage of industrial sectors and strong supporting capabilities, as well as the key attractive areas to talents. This will provide strong support for the development of China's local valve industry in terms of talent, market, management and support.

\section{Neway Valve (Suzhou) Co., Ltd}

Neway Valve was established in 1997 and headquartered in Suzhou, Jiangsu Province. As early as 2004, the annual income of Neway has exceeded 50 million US dollars and becoming the largest Chinese industrial valve manufacturer and exporter. Moreover, in 2014, it was successfully listed on the Shanghai Stock Exchange. Neway has been committed to producing and developing industrial valves with a full range of valve solutions. It has two valve equipment factories, four professional valve casting factories and one technology R\&D center in China, as well as five branch offices and multiple sales and service offices outside China. At present, Neway's annual production capacity reaches 600,000 units, and its sales revenue is nearly 2.5 billion yuan. The vision of Neway is to become an international valve manufacturer.

The information construction of Neway began as early as 2007. First, they completed the ERP system (SAP) implementation. In the next six years, they have completed the OA system to improve their standardization and efficiency of business process management. Then they deployed a Microsoft CRM system to manage and improve sales and customer service. In 2013, Neway implemented a PDM system that is specifically for product design and drawing version control. In addition, there is a WMS system to achieve three-dimensional management of warehouses. In addition, Neway has more forward-looking practices which are to interconnect these systems for data interaction. This greatly optimizes the intelligent management platform and provides a solid foundation of information technology in building smart factories.

In 2016, Neway's ball valve intelligent workshop was officially put into operation, and at the same time, their MES management system was officially launched. The integration of "Intelligence" and 
"Manufacturing" promotes the healthy development of enterprises. In May 2017, Neway received the certificate of the two-integrated management system issued by the Ministry of Industry and Information Technology.

\section{DHV Valve \& Foundry Co., Ltd.}

DHV Valve Casting was established in 2008, focusing on integrated operation of industrial valve development, manufacturing and casting (DHV, 2019). The largest castings product of them can reach 6 tons, their valve can reach a maximum diameter of $1200 \mathrm{~mm}$, and the largest pound can reach 2500 pounds. In the valve casting industry, their product development technology and manufacturing inspection capabilities are staying at the leading level both internationally and domestically. In 2017, the DHV performance report showed that the total operating income was near to 160 million yuan, and the operating income of 2018 has reached more than 300 million yuan. Now, DHV is the second Chinese valve company that was qualified as the global designated supplier of Dutch Shell, as well as only two Chinese suppliers have been used by Dutch Shell.

DHV has started planning smart manufacturing strategies and also completed preparatory work in the early stages. It included recruited IT management talents with nearly 20 years of experience in information technology construction of foreign companies, completed infrastructure upgrade of the overall network architecture, imported the best hyper-converged solutions on the market and invested heavily in rebuilding the data center. In addition to these completed preparations, DHV has also launched a new ERP project, using the D365 system of Microsoft with an international background, paving the way for future international development strategies. In addition, DHV has also increased its investment to add more production equipment. Not only a number of high-end CNC machines have been purchased, but also imported automated inspection equipment. These results have been well received by customers and passed the qualification review of Shell Global Strategic Tier 2 suppliers in 2019.

However, DHV is not always on the road to intelligent development. As early as 2016, the company focused on the development of intelligent production and invested a large sum of money in purchasing a fully automated electronic label management system. However, contrary to expectations, the system was abandoned after one year of implementation. After analysis, the main reason is the lack of professional overall strategic planning, a single bar code intelligent system will turn the collected data into an information island, it is impossible to interact up and down, as well as drive the entire business process. 


\subsection{Summary}

According to two RQs of this dissertation, the author conducts corresponding data collection through survey, interview and case analysis. It included 114 respondents surveyed and six interviewees, and two case studies of representative companies. Based on the above data and analysis, the author found that smart manufacturing development is the main strategic direction of China's local valve manufacturers. Moreover, three hypotheses related to development phases have been recognized by the respondents. 


\section{Discussions}

The purpose of this section is to discuss the key findings of two research questions. Their relevance and significance are discussed based on the previous literature review. Finally, the paper states what problems can be solved by research results, as well as its limitations.

\subsection{RQs with Key Results}

The two main purposes of this dissertation are to research the maturity of intelligent manufacturing development in China's local valve industry and the future feasible development approach.

For RQ1, the author collected 114 valid data of online surveys from the most developed coastal provinces in China. $94.6 \%$ of respondents' companies have begun planning or developing their intelligent manufacturing. According to the standards of smart manufacturing capability maturity issued by the Ministry of Industry and Information Technology, this survey contained 12 questions related to maturity. The comprehensive results showed that the maturity indicators of the respondents' companies were basically in the range of 0.8 to 1.8 . This also reflects the result that from the two dimensions of intelligence and manufacturing, the current intelligent maturity of local valve companies was not high, and the overall average level is still in the planning stage. Additionally, some companies have partially implemented standardized management.

For RQ2, the author used two methods of interviews and case studies to study the future viable smart manufacturing development path of local valve companies. The six respondents are from key departments of local Valve Company, as well as there are two case studies, which are very representative of local companies. The results of the analysis indicated that the local valve industry is under competitive pressure, and the customer required to meet the individualized design or flexible production. Moreover, the market has high demands on price, quality and future operation and maintenance of valve products. These market demands are driving the valve companies to implement intelligent production strategies. The analysis results also reflected that the development approach should be based on smart devices and automated production lines, combined with intelligent software to create a smart factory, and ultimately achieve the industrial Internet, cross-regional, crossenterprise collaborative development of the road.

\subsection{Findings and its Significance}

During the interviews, the respondents held similar standpoints on the development of local valve manufacturing in the future. They believed that the local valve industry is lack of concentration and relatively scattered. They do not have international brands and leading companies. The prerequisite 
for achieving international development goals is to improve production efficiency, ensure quality management and effectively control costs. The results of interviews also supported the study in LQ2 of the literature review. However, how to achieve this goal? Respondents also expressed the ir strategic goal is to develop smart manufacturing.

As mentioned in LQ1 of the literature review, a research report by the Chinese Academy of Engineering and Tsinghua University in 2018 illustrated three paradigms of smart manufacturing development, and China manufacturing industry was currently in the middle of the first and second phases. There is a certain digital foundation, but the integration of industrial networks and digital has not yet been realized. According to the interview results, most of the respondents' companies have completed the digitization stage. It included certain digital equipment and basic management software. However, a few well-developed valve companies have achieved the intelligent management of single modules, but have not fully completed the integration of digital and industrial Internet. Therefore, comparing with three paradigm models, the local valve industry was indeed in the middle of the first and second paradigms. In the context of the industry 4.0 era, referring to the standards of the White Paper from the Ministry of Industry and Information Technology, these respondents believed that their companies' maturity was only the level of primary intelligence that has been planned and partially standardization.

All of the above shows the significance of RQ2. In terms of the current situation and industry background, they urgently need a feasible development approach to help this industry emerge international brands and leading companies. But what is the feasible development approach?

From two case studies and interviews, the author found that as top one local valve industry, Neway has been informatization development for more than 10 years. From SAP to CRM, from PDM to MES, they are constantly improving their information platform. With the enactment of Made in China 2015, Neway's smart manufacturing development has also begun. From CNC machines to industrial robots, from intelligent inspection equipment to ball valve smart workshops, they are constantly moving forward in terms of smart devices. Neway's goal is to develop from first place in China to become a well-known international valve manufacturer. In order to achieve their strategic visions, their production scales have also undergone an expanding process. They have evolved from a centralized factory to a strategic structure with a clear division, included four foundries, two assembling factories and one R\&D center. In the LQ1 of the literature review, Deloitte pointed out three characteristics of intelligent manufacturing in its survey report in 2018. Over the years, Neway's development track has just evolved around flexible manufacturing and decentralization. Although Neway is still in the planning stage and partial standardization, its pace has already been ahead of 
other local valve companies. Their development experience also verified the three hypotheses of RQ2 in this dissertation. They based on smart devices developed smart workshops and aimed at achieving internal collaborative development with inter-regional and multi-factory.

While another valve company, DHV has ranked only 15 in local valve companies in 2017. They have rapid development of these two years and been certified as a global strategic supplier of Dutch Shell in 2019. In China, only two companies have obtained this certification, which also reflected their potential and development direction. The intelligent development of DHV started late. Although many $\mathrm{CNC}$ machines and intelligent inspection equipment have been introduced for a long time, they are very weak in intelligent systems. In 2016, DHV's first intelligent project (electronic barcode management) failed. The main reason was that the business management system at that time did not have a master plan and a financial module. That could not meet the needs of production operations. From a data analysis perspective, the missing data environment was unable to support accurate business decisions. In LQ1 of the literature review, Professor Chen from the University of Michigan proposed three basic elements of manufacturing technology: production efficiency, quality management and cost control. However, DHV's management system failed to meet these basic requirements, and intelligent devices cannot communicate effectively with the system. Failure is inevitable. During the interview with the interviewees, they also emphasized smart devices and intelligent systems, both of them are indispensable for intelligent development. The respondents said that they would be able to integrate data between physical factories and virtual factories through industrial network technology after they have smart devices and intelligent management systems. This was also the deep integration of industrialization and informatization proposed by Deloitte in their research report. Therefore, DHV decided to introduce talents and advanced ERP systems to develop their own intelligent path in 2018.

The results of this research suggest that local valve companies, such as DHV. Which started late but have good prospects for development, they could plan their own intelligent strategic plans based on these three hypothetical development approaches. The results of this research indicated that the development approach would reduce the risk of cost, avoid detours, ensure their development direction, and accelerate their development process.

\subsection{Research Limitations}

Although there are important discoveries revealed by these studies, there are also limitations. From the case study of Neway, the downside of their development plan was that it does not maximize the benefits of limited resources. This is also a common problem in local valve companies. 
Due to the particularity of the valve industry, their product has wide application and it is difficult to standardize directly. Taking shape as an example, the valve products required by different industrial scenes have different shapes, and many products cannot be completed by forging. Only casting can produce initial cast-steel work blank. However, casting is a difficult production technology of the process-oriented industry and low production capacity. Especially in terms of cost control and quality inspection, it is a problem for various valve factories. Neway has four foundries to supply its two assembly factories, even though it does not fully meet the needs of order delivery. The main reason was that the limitations of their molds have resulted in a low production capacity. Therefore, their foundry factories added from one to four, and still cannot be fully satisfied. To operate four foundries will raise a huge production cost and business risks. Therefore, Neway has not achieved a rational use of limited resources.

However, this problem has beyond the three hypothetical approaches, and there is currently no enterprise implementation. Therefore it is the limitation of this research. But the author believes that solving this proposition is the next step of innovation and future trends of intelligent manufacturing. Try to envision the future, and authors believe that the next step of the study can assume that the industrial Internet will be used to unite multiple-enterprises to realize an intelligent manufacturing integration platform across-regions, across-enterprises, and even across-industries. This is the future of the intelligent development of China's local valve industry. 


\section{Conclusion and Recommendations}

The purpose of this section is to summarize the main findings and their importance. Since the research on the development strategy of China's local valve industry, whatever in China and abroad is almost blank. Therefore, this research has actively promoted the development of this field. It has a positive instruction function for companies that are currently seeking a feasible development strategy. Besides, the final part of the conclusion in this section will propose the direction of further research in this study.

\subsection{Conclusions}

The new round of industrial revolution in the world has brought opportunities for the manufacturing industry in various countries. The Chinese local valve industry has also seized this opportunity and vigorously developed intelligent production. As the valve industry is also one of the most important suppliers to the construction projects, the sustainable development of the valve industry can affect the built environment. With intelligent production, resources can be allocated appropriately, the waste and cost can be reduced. Because the literature research in this field is almost blank, the main purpose of this research is to analyze the current intelligent maturity of the local valve industry and to study the intelligent development path suitable for the industry. The authors collected a large amount of data through a hybrid analysis of online surveys, interviews, and case studies. After analysis, the conclusions are as follows.

At present, the overall average level of intelligent maturity of China's local valve industry is still at the planning level. In addition, some companies with better development have begun to implement or complete some of the intelligent links. These include successful experiences and lessons learned from failures that have helped other valve manufacturers in the industry.

Regard to IM development approach of the local valve industry, first of all, smart devices are connected through information technology in the process of intelligent production to realize an automation production process. Secondly, through various types of sensing technology to collect data from the production process, to achieve intelligent factories. Then, the system analyzes the data, and realizes the interconnection between device and data through Industrial Ethernet, and automatically performs its next execution, and finally achieve their business strategy.

Additionally, the next research of the development approach could be considering the cross-regional, cross-enterprise, even cross-industry research to build an intelligent manufacturing integration platform through the Industrial Internet of Things. 


\subsection{Recommendations}

In the process of implementing smart manufacturing development, the author proposes to consider accelerating the development of a $5 \mathrm{G}$ information network, introducing high-end talents, setting up a special intelligent manufacturing management department, formulating clear strategic planning and phase objectives, and strengthening technical innovation cooperation with research institutes.

On the other hand, the author suggests that companies need to consider environmental protection and their own Corporation Social Responsibility (CSR). To rationally using limited resources to develop a new cooperation model of cross-company and cross-industry, avoiding repeated investment, reducing environmental pollution, improving efficiency and other social benefits. All of these will make China manufacturing industry move in a healthy direction. 


\section{References}

Adler, P. A., Adler, P., \& Weiss, R. S. (1995), "Learning from Strangers: The Art and Method of Qualitative Interview Studies", Contemporary Sociology, Vol. 24 No. 3, pp. 420, https://doi.org/10.2307/2076552.

Chen, Y. (2017), "Integrated and Intelligent Manufacturing: Perspectives and Enablers", Engineering, Vol.3 No. 5, pp. 588-595, https://doi.org/10.1016/J.ENG.2017.04.009.

Chinese State Council (2015), "Made in China 2025", available at: http $/ /$ search.ebscohost.com/login.asp $x$ ?direct=true $\& d b=$ edscqv $\& A N=$ edscqv $.664728516 \&$ site $=$ eds -live\&scope $=$ site (accessed 25 March 2020).

DHV. (2019), "DHV Valve World”, available at: http://www.dhvfoundry.com/en/default.aspx (accessed 13 March 2020).

Gao, T. (2018), "Intelligent Future | Intelligent Manufacturing in the Fourth Industrial Revolution", available at: https://www2.deloitte.com/cn/zh/pages/innovation/articles/smart-manufacturing-inindustry-4-0.html (accessed 31 March 2020).

Huiwen, F. (2016). Hot Topics and Forecast on the Trends of Global Manufacturing, Beijing Posts \& Telecom Press, Beijing, China. ISBN: 9787115429001.

Ji, Z. (2015), "Intelligent manufacturing -- the main direction of "Made in China 2025", China Mechanical Engineering, Vol. 26 No. 17, pp. 2273-2284, http//doi.org/10.3969/j.issn.1004132X.2015.17.001.

Kagermann H, Wahlster W and Helbig J (2013), "Recommendations for implementing the strategic initiative INDUSTRIE 4.0", Federal Ministry of Education and Research, Frankfurt, Germany, available at:

http//www.acatech.de/fileadmin/user_upload/Baumstruktur_nach_Website/Acatech/root/de/Materi al_fuer_Sonderseiten/Industrie_4.0/Final_report_Industrie_4.0_accessible.pdf (accessed 31 March 2020)

Keqiang, L. (2017), "Made in China 2025: Turn China Manufacturing Power from Volume to Value", available at: http://www.gov.cn/xinwen/2017-08/10/content_5216727.htm (accessed 31 March 2020).

Lee, X. E. (2015), "Made in China 2025: A New Era for Chinese Manufacturing", available at: http//knowledge.ckgsb.edu.cn/2015/09/02/technology/made-in-china-2025-a-new-era-for-chinesemanufacturing/ (accessed 30 March 2020).

Lukač, D. (2015), 'The fourth ICT-based industrial revolution 'Industry 4.0' - HMI and the case of CAE/CAD innovation with EPLAN P8", 2015 23rd Telecommunications Forum Telfor (TELFOR), Belgrade, Serbia, pp. 835-838, available at: http//doi.org/10.1109/TELFOR.2015.7377595.

Miao, W. (2017), "Report of the State Council on Promoting Supply-side Structural Reform and Accelerating the Transformation and Upgrading of Manufacturing Industry", Twenty-seventh 
meeting of the standing committee of the twelfth National People's Congress, 24 April, Beijing, available at: http://www.jcec.cn/cont.php?cid=1871 (accessed 31 March 2020).

Miranda, J., Ponce, P., Molina, A., \& Wright, P. (2019), "Sensing, smart and sustainable technologies for Agri-Food 4.0". Computers in Industry, Vol. 108, pp.21-36, https://doi.org/10.1016/j.compind.2019.02.002

National Bureau of Statistics of China. (2017), "National Data",a vailable at: http $/ /$ data.stats.gov.cn/search.htm?s=valve (accessed 6 April 2020).

Obama, B. (2011), "President Obama Launches Advanced Manufacturing Partnership", available at: https://obamawhitehouse.archives.gov/the-press-office/2011/06/24/president-obama-launchesadvanced-manufacturing-partnership (accessed 30 March 2020).

Shen, R. (2018), "Expanding the SCO development path and promoting international capacity cooperation”, China Science and Technology Forum, Vol. 2018 No. 11, pp. 189-189, https://doi.org/10.13580/j.cnki.fstc.2018.11.001.

Stock, T., \& Seliger, G. (2016), "Opportunities of sustainable manufacturing in industry 4.0". Procedia Cirp, Vol. 40, pp. 536-541, https://doi.org/10.1016/j.procir.2016.01.129.

Taki, H. (2017), "Towards technological innovation of Society 5.0”, J Inst Electr Eng Jpn, Vol. 137 No. 5, pp. 275, https//doi.org/10.1541/ieejjournal.137.275.

Tian, J. (2017), "The new power of China's smart manufacturing__ecode logo builds the industrial Internet ecosystem”, China's automatic identification technology, Vol. 2017 No. 2, pp. 50-52, http://doi.org/10.3969/j.issn.1673-6362.2017.02.009.

Wen, S. (2018), “China Green Intelligent High-end Valve Production Line Project Officially Launched”, available at: https://www.xianjichina.com/special/detail_334036.html (accessed 9 April 2020).

Wong, Johnny and Li, Heng (2009), "A framework for analyzing system intelligence of the building control system: a study of the integrated building management system". In: 3rd International Conference on Smart and Sustainable Built Environments (SASBE 2009), 15-19 June 2009, Delft, Netherlands, available at: http://eprints.qut.edu.au/48433/ (accessed 31 March 2020).

Wright, P. K., and Bourne, D. A., (1988), Manufacturing Intelligence, Addison-Wesley, Reading, Mass, USA.

Zhou, J., Li, P., Zhou, Y., Wang, B., Zang, J., Meng, L. (2018), "Toward New-Generation Intelligent Manufacturing”, Engineering, Vol.4 No. 1, pp. 11-20, https://doi.org/10.1016/j.eng.2018.01.002. 


\section{List of Abbreviations}

CNC Computer Numerical Controller

CPS Cyber-physical System

ICT Information and Communications Technology

IM Intelligent Manufacturing

IMS Intelligent Manufacturing System

IIoT Industrial Internet of Things

III The integration of informatization and industrialization

IoT Internet of Things

LQ Literature Question

MIIT the Ministry of Industry and Information Technology

OTC Over-the-counter

PLC Programmable Logic Controller

RQ Research Question

SQ Survey Question 